\title{
Sistemas de Informação apoiando a gestão do trabalho em saúde
}

\author{
Information Systems supporting the management work in health
}

Sistemas de Información Que apoyan la gestión del trabajo en salud

\section{Gladys Amélia Véles Benito', Ana Paula Licheski'}

'Universdade do Vale do Itajaí. Curso de Graduação em Enfermagem. Itajaí, SC

Submissão: 24/04/2008

Aprovação: 15/04/2009

\section{RESUMO}

O artigo apresenta alguns aspectos sobre a relevância dos sistemas de informação como ferramenta de apoio à gestão do trabalho dos profissionais de saúde, uma vez que é um recurso computacional capaz de potencializar a busca de conhecimento. Sabe-se Que os sistemas de informação disponibilizam de forma rápida, fácil e segura as informações, permitindo Que os profissionais da saúde busQuem conhecimentos e se tornem capacitados, criativos e competentes para atuar com a complexidade do trabalho em saúde dentro do sistema de saúde brasileiro visando consolidar a política do SUS. Reflete-se sobre o que seja a gestão do trabalho em saúde e como os sistemas de informação vêm contribuir para o fortalecimento de ações e processos de saúde nesta área.

Descritores: Sistemas de Informação; Gestão em Saúde; Informática em enfermagem.

\section{ABSTRACT}

The article presents some aspects on the relevance of the information systems as tool of support to the management of the work of the health professionals, a time that is a computational resource capable to potential the knowledge search. Know that the information systems available of fast form, easy and insurance the information, allowing that the professionals of the health search knowledge and if become able, creative and competent to inside act with the complexity of the work in health of the Brazilian system of health aiming at to consolidate the politics of the National Health System. It is reflected on what it is the management of the work in health and as the information systems they come contribute for the fortify of action and processes of health in this area.

Descritors: Information Systems.; Health management; Nursing informatics.

\section{RESUMEN}

El articulo describe algunos aspectos sobre la importancia de la información como herramienta de apoyo en la gestión del trabajo de los profesionales de salud, siendo este un recurso computacional que es capaz de potencializar la busca del conocimiento. Sabemos Que los sistemas de información disponibilizan la información de una forma rápida, fácil y segura, permitiendo Que los profesionales de salud busquen conocimientos y se tornen capacitados, creativos e competentes para actuar con la complejidad del trabajo en salud del sistema de salud brasilero, visando consolidar las politicas del SUS. Se reflexiona sobre lo que sea la gestión del trabajo en salud y como los sistemas de la información vienen contribuir para el fortalecimiento de las acciones y de los procesos de salud en esta área.

Descriptores: Sistemas de información; Gestión en salud; Enfermería informática. 


\section{INTRODUÇÃO}

Num mundo em constante evolução tecnológica e modernização das atividades, tornou-se importante que as entidades de Qualquer área de estudo, sejam públicas ou privadas, se adaptassem às novas perspectivas do mercado de trabalho. Com isso, criaram-se novas formas de disseminação das informações e rapidez na transmissão de conhecimento. Esses avanços resultaram na "Era da Informação" Que está dando origem à "Era do Conhecimento". A partir disso, houve a criação dos sistemas de informação, Que podem ser entendidos como QualQuer software encontrado na internet, sendo possível o envio e recebimento de informações de uma ou mais pessoas, ou ainda, entre órgãos ${ }^{(1)}$. Os sistemas e informação tornaram-se um dos principais recursos computacionais capazes de propagar de maneira rápida, fácil e segura as informações necessárias para mediar a aprendizagem e auxiliar os profissionais no processo de trabalho.

Os sistemas de informação, enquanto instrumentos de trabalho na saúde, são importantes recursos computacionais de apoio às ações administrativo-burocráticas e àQuelas ancoradas em conhecimentos técnico-científicos, sobretudo as que dependem de informações atualizadas. Estes são capazes de estruturar, operacionalizar, supervisionar, controlar e avaliar o desempenho do departamento/serviço/unidade ${ }^{(2-6)}$. Para os profissionais da saúde, a necessidade de manter-se atualizado é fundamental para aprimorar sua prestação de serviços, garantindo-a com Qualidade à clientela ${ }^{(6)}$. Quanto mais conscientizados nos tornamos, mais capacitados estamos para ser anunciadores e denunciadores, frente ao compromisso Que assumimos, permitindo desvendar a realidade, procurando desmascarar sua mitificação e alcançar a plena realização do trabalho humano com ações de transformação da realidade ${ }^{(5)}$.

Com este novo instrumento de trabalho em saúde, pode-se afirmar Que os profissionais de saúde poderiam estar beneficiando as suas práticas gerenciais atendendo os interesses no Que envolvem o trabalho e o trabalhador. A gestão do trabalho inclui ações e relações de gestão, regulação e regulamentação da atividade exercida. Dentre elas podem ser citadas: educação permanente em saúde, diretrizes de trabalho, modelos de atenção, plano de carreira, cargos e salários, saúde ocupacional, etc ${ }^{(7)}$.

Com isso, uma ferramenta, Que garanta atualização constante e fácil acessibilidade, permitiria aos profissionais, Que planejassem e organizassem as suas ações nos seus processos de trabalho, adQuirindo e aplicando os conhecimentos teóricos e práticos nas suas intervenções, buscando a solução dos problemas, e a Qualidade do trabalho e do trabalhador. A utilização dos sistemas de informação no processo de tomada de decisão aumenta a eficiência dos serviços prestados a clientela, pois, disponibiliza profissionais capacitados e atualizados para atuarem nos serviços de saúde.

Vale evidenciar, Que uma das grandes dificuldades observadas na aplicação dos sistemas de informação, é a aceitação dos profissionais em relação a estes recursos computacionais. Essa resistência se dá por diferentes fatores com: a falta de informação Quanto ao verdadeiro objetivo dos sistemas de informação, ausência de um treinamento adequado para a equipe de saúde, falta de motivação. ${ }^{3}$ Porém, é preciso insistir no fato de Que as vantagens trazidas pelos sistemas de informação são imensas, permitindo Que os profissionais mudem suas perspectivas em relação a esses novos meios tecnológicos.

Este artigo procura apresentar, discutir e refletir algumas Questões sobre a relevância dos sistemas de informação como ferramenta de apoio à gestão do trabalho dos profissionais de saúde, capaz de oferecer-lhes recursos para a tomada de decisão e gerenciamento dos múltiplos processos de trabalho por eles desenvolvidos na grande amplitude do trabalho em saúde.

Neste sentido, a informação e o seu fluxo articulado das informações no processo de trabalho em saúde devem ser visualizados como o eixo norteador para a potencialização e efetividade das ações de saúde, sobretudo na rede de atenção à saúde. Com a globalização e desenvolvimento tecnológico acelerado os processos de trabalho estão se tornando cada vez mais desafiadores e complexos para os profissionais, requerendo destes o desenvolvimento de competências Que venham a se agregar às já adeuiridas durante sua formação e experiência profissional.

\section{SOBRE A GESTÃO DO TRABALHO EM SAÚDE}

O trabalho é visto como um processo de trocas, criatividade, co-participação e co-responsabilização, de enriQuecimento e comprometimento mútuos. Já a gestão de trabalho trata da relação entre o trabalho e a participação do trabalhador como ponto fundamental para a eficiência do sistema. Assim, o trabalhador é percebido com um sujeito e agente transformador de seu ambiente e não apenas um recurso humano realizador de tarefas previamente estabelecidas pelas esferas maiores ${ }^{(8)}$.

Atualmente, a organização do trabalho tem como característica a transição do modelo do trabalho prescrito, Que não permite aos trabalhadores ter autonomia sobre suas intervenções, para o modelo tecnológico, baseado nas práticas apoiados no conhecimento científico e a Qualificação profissional. A partir disso, tem-se a necessidade de redefinir as formas de formar, recrutar, selecionar, Qualificar e manter os profissionais em suas respectivas atividades, criando novas alternativas de incorporação e a remuneração da força de trabalho, cada vez mais especializada, sendo incorporadas como instrumento essenciais na gestão do trabalho ${ }^{(9)}$.

A gestão do trabalho pressupõe as Questões Que envolvem a valorização do trabalhador da saúde e do seu trabalho, dando atenção especial: a desprecarização do trabalho, pois muitos trabalhadores submetem-se às grandes jornadas de trabalho, práticas sem equipamentos adequados, ambientes precários, resultando na falta de compromisso desses profissionais com os serviços, diminuindo a eualidade e causando grande rotatividade do Quadro de funcionários, impedindo a formação de vínculos entre os trabalhadores e a clientela, além de problemas com Questões trabalhistas.

Dentre as Questões trabalhistas pode-se citar; o Plano de Carreira, Cargos e Salários, Que tem o objetivo de valorizar a carreira; tratase de um plano atualizado Que garanta a mobilidade, ou seja, remunerações com partes fixas e outra variável, de forma Que possa estar privilegiando o esforço à formação, Qualificação e avaliação do desempenho; a capacitação e educação permanente dos trabalhadores, Que permite a atualização e capacitação dos profissionais, permitindo Que aos profissionais se tornem mais habilitados para a atuação nos serviços; os espaços de discussão e negociação das relações de trabalho em saúde, com mesas de 
negociação permanente e comissões locais de negociação de condições de trabalho Que permitam discussões entre profissionais da saúde e gestores, objetivando a construção coletiva de respostas relacionadas com a regulação do trabalho em saúde, tendo como desafio atender as necessidades dos profissionais da saúde e garantir Que o serviço seja adeQuado para a sociedade; humanização da Qualidade do trabalho, tanto para os profissionais Quanto para sua clientela $^{(8,9)}$.

\section{SOBRE OS SISTEMAS DE INFORMAÇÃO}

Trabalhando com o conceito de sistema de informação, constatou-se Que a idéia desta palavra tomou corpo Quando começou a ser associada com a informática, surgindo logo após a Primeira Guerra Mundial. Isto só foi possível porque ocorreu um crescimento das organizações havendo a necessidade de controlar essas ações, outro motivo foi a evolução da indústria eletrônica, Que possibilitou a produção de computadores, e a última forma impulsionadora foi o relativo pensamento científico e filosófico, Que buscava compreender os novos fenômenos, desafios e transformações aceleradas do mundo ${ }^{(10)}$.

Sistema de Informação pode ser entendido como um conjunto de procedimentos Que buscam transmitir informações entre pessoas e órgãos através de QualQuer meio ${ }^{(3)}$.

Os sistemas podem ser classificados Quanto a sua constituição: físicos ou abstratos, sendo Que o primeiro reporta-se aos equipamentos, objetos (hardware), e o segundo composto de idéias e hipóteses (software), Quanto a sua natureza: abertos e fechados, dependendo se apresentam ou não intercâmbio com o meio ambiente $\mathrm{e}^{(10)}$.

Tomando esses conceitos de sistema de informação, pode-se considerar Que Quando relacionados à saúde, atuam como partes Que dão conotação ao plano, ao método, dão ordem, arranjo e Que o antônimo de sistema é o caos ${ }^{(10)}$.

Sistema de Informação em Saúde é um mecanismo de coleta, processamento, análise e transmissão de informação necessária para se organizar e operar os serviços de saúde e, também, para a investigação e o planejamento com vistas ao controle de doenças e Que o propósito do sistema de informação em saúde é selecionar os dados pertinentes a esses serviços e transformá-los na informação necessária para o processo de decisões, próprio das organizações e indivíduos Que planejam, financiam, administram, provêem, medem e avaliam os serviços de saúde"(10).

Neste sentido os sistemas de informação em saúde devem permitir Que os trabalhadores e a população tenham acesso às atualidades, à profundidade das informações, para Que sirva de apoio no processo decisório ${ }^{(11)}$. Um dos recursos computacionais Que merece destaque atualmente é a internet, Que se apresenta como uma ferramenta essencial para a propagação da informação e colaboração no campo de pesQuisa. A agilidade, rapidez e alcance internacional das informações permitem a maior transação de informações, integração entre profissionais de diversos lugares e divulgação de experiências ${ }^{(1)}$.

Em meados da década de 90, a internet começou a ganhar seu espaço na área da saúde, sendo utilizado pelos profissionais com o propósito tradicionais como e-mails, listas de discussão, mecanismos de busca, entre outros. Porém nos últimos anos a internet tem oferecido maiores oportunidades para busca de informações, provocando impactos significativos nos cenários da educação, assistência e pesquisa em saúde ${ }^{(2)}$.

Internet é um ambiente capaz de mediar à aprendizagem, facilitar a interação social, instrumento auxiliador na construção de pontes de análise, tomada de consciência, compreensão e aumento da competência científica; caracteriza-se pela sua flexibilidade, possibilitando a construção de cominhos capazes de buscar informações, ou ainda, diálogos sobre algum tema, tendo a chance de encontrar e comparar várias versões, formando novas opiniões; poderá tornar-se um elemento de transformação cultural, conduzindo o processo de aprendizagem individual de coletivo ${ }^{(1)}$.

\section{SISTEMAS DE INFORMAÇÃO NA GESTÃO DO TRABALHO EM SAÚDE}

Observa-se que todas as áreas já sentem a necessidade de introduzir a informática, principalmente nas instituições de saúde. Assim, as várias áreas de saúde estarão sendo beneficiadas com a implementação de sistemas de saúde. Um dos objetivos principais de um sistema de informação é promover a Qualidade da assistência, aprimorando a administração da informação nas unidades de internação, e gerenciamento da gestão do trabalho. Deve-se considerar ainda, Que esses sistemas de informação em saúde, resultarão numa documentação melhorada para propósitos legais e de pesquisa relacionados à escrituração( ${ }^{(3)}$.

Concretamente, o conhecimento é o instrumento mais poderoso do trabalhador, seja para sua liberdade, ou para a execução de atividades e técnicas, com a finalidade de obter o produto final, Que na saúde trata-se da própria prestação da assistência( ${ }^{(1)}$.

A partir disso, pode-se considerar que os sistemas de informação trazem como vantagens para os profissionais da saúde, o favorecimento da aprendizagem, conduzindo de maneira adequada e personalizada para cada indivíduo, de forma independente e no horário e tempo necessário; permitem a atualização dos sistemas de acordo com os avanços apresentados na área; de fácil acesso, pois vale lembrar Que o computador é consistente, paciente, tolerante com todos, sem distinção ${ }^{(4)}$.

No cenário atual dos serviços de saúde, a informação tornou-se a base para o desenvolvimento das instituições, tornando os sistemas de informação um instrumento essencial para a gestão do trabalho, contribuindo no Que diz respeito às ações de gerenciamento, monitoramento, desenvolvimento e avaliação do trabalho em saúde. Neste sentido, a informatização ganha relevância, pois, encurta os fluxos, favorecendo a comunicação entre setores da organização, departamentos e unidades, representando, portanto, uma base concreta para o processo gerencial. Vale ressaltar, Que além da contribuição no processo gerencial, a internet, destacando os sistemas de informação, são ótimos ambientes de aprendizado, pois, possibilitam processos de capacitação e formação simultâneos, além da flexibilidade Quanto ao local, Que permite interessante combinação entre estudo e trabalho, otimizando o tempo do próprio profissional( $^{(8)}$.

Acredita-se Que os sistemas de informação Que Qualificam os profissionais da saúde para Que possam executar as tarefas com Qualidade, e sejam usados como ferramenta de trabalho, serão capazes de transformar e sustentar o Sistema Único de Saúde, 
dando retornos positivos espetaculares a curto $\operatorname{prazo}^{(9)}$.

\section{CONSIDERAÇÕES FINAIS}

A relevância dos sistemas de informação como apoio à gestão do trabalho em saúde, seja, na área clínica assistencial, ou na administrativa-burocrática e de gestão torna-se inegável. Todas as áreas e/ou campos de conhecimentos Que venham a trabalhar com saúde, como a medicina, enfermagem, odontologia, fisioterapia, psicologia, fonoaudiologia, serviço social, educação física, engenharias, administração, entre outras; podem vir a usufruir das informações contidas nos sistemas, utilizando-as como uma ferramenta de auxílio no seu processo de trabalho. Pois estas são capazes de acelerar a efetividade do processo de identificação de problemas individuais e coletivos; potencializando a resolubilidade das necessidades e/ou situações Que venham a surgir nos diversos cenários e/ou ambientes de trabalho em saúde.

É conveniente ressaltar Que, a partir da rapidez, acesso e flexibilidade da internet, onde estão disponibilizados os sistemas de informação, este se tornou o maior meio para disseminação de informação, e conseQüentemente de conhecimento, pois através desses sistemas, é possível a comunicação de pessoas com diferentes objetivos, permitindo discussões e relacionamentos múltiplos; minimizando barreiras culturais, de infraestrutura, distância e tempo, disponibilidade de acesso, permitindo maior troca de informações, e aQuisição de conhecimentos de uma forma mais ágil e dinâmica.

Os sistemas de informação Que disponibilizam as informações de forma organizada e de fácil acessibilidade tornam-se recursos tecnológicos capazes de potencializar a busca, o acesso e principalmente a efetividade das ações dos profissionais de saúde, tornando-se uma ferramenta de apoio às atividades, auxiliando na tomada de decisão e aQuisição de conhecimento, e como resultado, tem-se profissionais mais capacitados, criativos, capazes de mudar a realidade e melhorar o atendimento dos serviços de saúde através de ações de inovação de processos de saúde potencializando assim suas competências pessoais e coletivas no trabalho em saúde.

\section{REFERÊNCIAS}

I. Martineli RMF. Tecnologia da informação na construção do conhecimento: uma abordagem a partir do modelo de Nonaka \& Takeuchi [dissertação]. Florianópolis (SC): Universidade Federal de Santa Catarina, Programa de Pós-Graduação em Engenharia de Produção; 2001 .

2. Barbosa SFF, Dal Sasso GTM. Internet e saúde: um guia para os profissionais. Blumenau: Nova Letra; 2007.

3. Benito GAV. Concepção de um sistema de informação de apoio à supervisão da assistência em enfermagem hospitalar: uma abordagem da ergonomia cognitiva. [tese]. Florianópolis (SC): Universidade Federal de Santa Catarina, Programa de PósGraduação em Engenharia de Produção; 2001 .

4. Benito GAV. O aluno frente ao ensino da informática na enfermagem. Texto Contexto Enferm 2000; 9(1): 79-92.

5. Machado MFAS, Monteiro EMLM, Queiroz DT, Vieira NFC, Barroso MGT. Integralidade, formação de saúde, educação em saúde e as propostas do SUS - uma revisão conceitual. Ciência Saúde Coletiva 2007; I2(2): 335-42.

6. Santos MS. Informatização de atividades administrativo- burocráticas de enfermagem relacionadas ao gerenciamento da assistência [tese]. Ribeirão Preto (SP): Universidade de São Paulo, Escola de Enfermagem de Ribeirão Preto; 2003.

7. Pierantoni C. As reformas do Estado, da saúde e recursos humanos: limites e possibilidades. Ciência Saúde Coletiva 200 I; 6(1): 34l-6I.

8. Ministério da Saúde (BR). Manual de organização da atenção básica. Brasília; 1999. [citado em 01 abr 2007]. Disponível em: http://dtr2004.saude.gov.br/dab/caadab/documentos/ manual_organizacao_ab.pdf.

9. Ministério da Saúde (BR). Gestão do trabalho na saúde. Brasília; 2007. [citado em 15 jun 2007]. Disponível em: http:// www.conass.org.br/?page $=$ progestores.

10. Pinto, IC. Os sistemas públicos de informação em saúde na tomada de decisão - rede básica de saúde do município de Ribeirão Preto-SP [tese]. Ribeirão Preto (SP): Universidade de São Paulo, Escola de Enfermagem de Ribeirão Preto; 2000.

I I. Leopardi MT. O processo de trabalho em saúde: organização e subjetividade. Florianópolis: Papa-Livros; 1999. 